\title{
A Study on the Development Paths of Special Agricultural Products Industrialization in Underdeveloped Areas
}

\author{
Luan $\mathrm{Hu}^{1, \mathrm{a}}$, Qing Wang ${ }^{2, \mathrm{~b}}$ (Correspondence Author) \\ ${ }^{1}$ Huanggang Normal University, Huanggang City, Hubei Province, 438800, China \\ ${ }^{2}$ Dabie Mountain Agricultural Resources Utilization of Collaborative Innovation Center in Hubei \\ Province, Huanggang City, Hubei Province, 438800, China \\ aemail:45417309@qq.com \\ bemail: 304506303@qq.com
}

Keywords:Underdeveloped Areas; Distinctive Agricultural Products; Industrialization; Development Path

\begin{abstract}
The underdeveloped areas are characterized by high proportion of agriculture, distinctive agricultural resources, and unique advantage of regional economic development, which provides favorable conditions and vast space for the development of industrialization management of distinctive agricultural products. Faced with the fierce market competition, the active implementation of industrialization management is of great significance to bring the advantages of distinctive agricultural resources in the underdeveloped areas into full play and realize the sustainable development of agriculture and rural economy. In this paper, based on the author's learning and practical experience, we pointed out the problems in the industrialization management of distinctive agricultural products in underdeveloped areas, and then put forward the specific development paths.
\end{abstract}

\section{Introduction}

Huanggang is a big agricultural city in Hubei province, which has a series of well-known agricultural products with highly regional characteristics because of its unique natural conditions and traditional processing technology. If we can promote the industrialization of these distinctive agricultural products according to the local conditions, form the organic combination and mutual promotion mechanism of planting, processing and marketing, and promote the process of its commercialization, specialization, environmentalization and modernization of production and processing, which is of great significance for increasing the income of the farmers, accelerating the pace of urbanization of rural areas, and achieving sustainable development of agriculture and rural economy[1].

\section{Problems in Industrialization Management of Distinctive Agricultural Products in Underdeveloped Areas}

\subsection{Production base construction hysteresis}

In recent years, the production base of distinctive agricultural products in Huanggang city has continuously expanded and had a certain scale with the drive of the agricultural products processing enterprises. However, its production and management is still not out of the traditional agricultural mode namely household production and decentralized management. Besides, the production and operation pattern has not formed that the development is based on regional advantageous industries and leading products, the large markets drive the large leading industries, the large leading industries drive the large base, and the large base is connected with the large groups. In particular, the base constructions of tea and Chinese herbal medicine have not yet made a substantial breakthrough. Their total production is insufficient, which is difficult to meet the business needs of raw materials[2]. The interests of enterprises, bases and farmers are not closely linked. The enterprises cannot realize the full-capacity production because of the lack of stable, batch of and standardized supply of raw 
materials. The lack of continuous and stable drive of leading enterprises results in the significant price fluctuations, which dampens the production enthusiasm of the farmers.

\subsection{Low enterprises' development level}

The production and operation scales of most agricultural products processing enterprises are small. The drive ability is weak, and the ability to resist market risk is low. Most companies still follows the traditional processing technology, and have no independent research center and specialized research funds. Their scientific research funding is not enough, and scientific research mechanism is imperfect[3]. The role of human resources in scientific research team is not fully played. Their scientific research and innovation ability are weak. The self-owned proprietary products are very few. The abilities of enterprises that the new products are timely developed to meet the consumption demand of domestic and international market are not strong. The scientific and technological support abilities for the continuous development of deep processing of agricultural products is not strong.

\subsection{Obvious brand construction gap}

In recent years, Huanggang City has increased the intensity in brand cultivation, and achieved some achievements. However, the gap with that of the province is obvious. In addition, the situation characterized by lack of coordination and admixture of good and evil in striving for brands and the use of trademarks is more serious, especially in tea industry. The same product with the same quality in the same region has a number of different titles. Once a brand becomes famous, many similar products regardless of the quality of production and the difference of standard all rush to label the brand as their own one so that a sense of disorder is perceived by the outside world towards the production and operation of the product, which ultimately damages the reputation and leads to a total loss of the competing parties. For example, Luotian chestnut is a local well-known distinctive agricultural product, but there are many companies using this title, which leads to the failure in forming their own distinctive product[4].

\subsection{No risk-sharing mechanism}

At present, there are no standard contracts among the growers, processing enterprises and professional market. They do things in their own ways, which is only a market transaction relationship. The government's protective price is also a dead letter. Therefore, the industrial chains are not formed in the processing enterprises and professional market belts. The production and sale are loosely linked. This situation not only mismatches the fierce market competition, but also brings huge losses to the growers in the event of natural disasters and market risks, which results in the farmers generating doubts towards the large area of planting, and seriously affects the development of distinct agricultural products industrialization.

\section{Path Choice of Agricultural Industrialization Development}

\subsection{The government should change its functions and strengthen the support to the distinctive agricultural industrialization}

The agricultural industrialization in underdeveloped areas is still in its infancy, which urgently needs the strong support and active guidance of the government. The government should explore the development regularities and operational mechanism of distinctive agricultural products industrialization under the condition of socialist market economy, look for the development path of ditinctive agricultural products industrialization which is suitable for actual situation of the city, create a flexible market economy environment, and support the development of distinctive agricultural products industrialization in policy, fund, prices and so on.

(1) Credit support. The government can encourage all trades and industries, especially the prenatal and post-production enterprises of distinctive agricultural products, to directly sign the credit contract with the peasant households through interest subsidy, guarantee, etc, and invest the capital into distinctive agriculture by means of loan subsidy and payment. (2) Tax support. A certain relief of income tax can be given to the companies joining the distinctive agricultural industrialization and integration, which aims at protecting the income of the integration organizations so that they can quickly accumulate assets. (3) Financial support. The goverment policy about increasing agricultural 
investments should be conscientiously implemented, and the investments should be put into place. At the same time, we should open up new investment channels, establish a government-guiding, multi-supporting and enterprise-based input mechanism, and guide and gather social funds to support the development of distinctive agricultural products industrialization in accordance with the principle of "who develops, who invests, and who benefits". (4) Price support. On the one hand, the government should straighten out the price relationship between industrial and agricultural products, reduce the scissors difference between industrial and agricultural products, improve the purchase and selling prices of the distinctive agricultural products. On the other hand, the government should stipulate the minimum protection price of distinctive agricultural products and protect the enthusiasm of peasants' production.

\subsection{Highlight the leading industries according to resource advantages}

In the process of distinctive agricultural products industrialization, the underdeveloped areas should pay special attention to the advantages of local resources, promote the formation of regional distinctive economy, and gradually establish the leading agricultural industry which is suitable for the local actual situation. In regards to the selection of varieties, the planting area should be determined and divided according to the appropriate soil and climate types. The leading enterprises and professional market should be placed in the traffic gathering area, and urban areas with rich water resources and better functions. For the comparative advantage of distinctive agricultural products, it is necessary to look at not only the price, but also the quality, analyze not only a product, but also the specific varieties, and consider not only the current situation, but also the source of the market competition. From this perspective, if the distinctive agricultural products in the underdeveloped areas want to obtain comparative advantage, they must maintain their characteristics of green and environmental friendliness, health, difference and low price brought by cheap labor. Only in this way can the industrialization management of distinctive agricultural products become a realistic and effective way to promote agricultural structural adjustment and farmers' incomes increase in underdeveloped areas[5].

\subsection{Rely on scientific and technological innovation, and achieve sustainable development of distinctive agricultural products}

First, increase investment in agricultural science and technology. In addition to increasing the national financial allocation, the methods can be used that the agricultural companies are listed for financing, and agricultural high-tech industry venture capital funds are set up. Besides, various preferential policies can be used to encourage technological investment in various forms. Especially, the global, critical, prospective and strategic system engineerings with major technological innovation, improvements, and support should be included in technological special funds investment in the process of processing industrialization of distinctive agricultural products[6].

Second, guide, cultivate and support private scientific research institutions, and promote the level of local agriculture via science and technology. We should encourage large-scale leading enterprises to carry out wide scientific and technological cooperation with universities and research institutes, and take the road of industry-university-research collaboration and the integration of production and scientific research. We should set up technological breakthrough and development institutions by making full use of various research resources and existing research and development achievements, reinforce high-tech application and promotion, expand international exchanges, introduce foreign advanced technology, process, equipment and management experience, strengthen research and development of deep and fine processing technology of distinctive agricultural products, and improve the level of deep processing of agricultural products. We should pay special attention to research and development of key technologies of fine processing of distinctive agricultural products.

Third, accelerate the technological transformation pace of traditional enterprises, and promote enterprises development via technological innovitation. we should practically increase the technological level of processing, promote the upgrading of local agricultural products processing industry, and form a batch of brand agricultural products with high technological content and regional characteristics through the introduction of domestic and foreign advanced technology, process, equipment and technical personnel[7]. 
Fourth, improve the scientific research and technology promotion system of the distinctive agricultural products. On the one hand, we should rely on scientific research institutes and powerful enterprises to establish Dazhou distinctive agricultural production and processing technology training center, cultivate the leaders and promotion team of agricultural science and technology. On the other hand, through the education of a college student in a village and various training carrier such as vocational schools, scientific and technological activities, township demonstration bases, we should establish the training system of cultivating the new farmers via multi-channels, multi-levels and multi-forms, strengthen the technological education and training of the farmers, enhance the farmers' technological and market awareness, create a group of modern new farmers who have a good basic education and understands both agricultural techniques and business operations, and make them be the backbone of developing production and processing industry of distinctive agricultural products.

\section{Summary}

Overall, the current development of distinctive agricultural products industrialization in the city of Huanggang is just at the initial stage. Its scale is generally small, and its own strength is not strong. Therefore, it is necessary to further encourage and support the farmers from the policy level to independently establish various professional cooperatives, professional associations and other forms of cooperative organizations, form the mechanism of organic integration and mutual promotion of planting, processing and marketing, and promote the process of its commercialization, specialization, environmentalization and modernization of production and processing.

\section{Acknowledgement}

Project of Humanities and Social Science of Educational Commission in Hubei Province(15D115); Excellent young talents Program of Educational Commission in Hubei Province(Q20162907); High-Level Project Cultivate Fund of Huanggang Normal University; Humanities and social sciences research project of Hubei Provincial Department of Education(17Q177) .

\section{References}

[1] LIU Hongyuan, LIU Qiuhong. The predicament and tactics of rural characteristic industry development in underdeveloped area. Rural Economy, (12), pp.57-61, 2015.

[2] ZHOU Xiang, ZHOU Ailian. Analysis of the advantages and disadvantages of special agricultural products industrialization development in Gansu province. Journal of Library and Information Sciences in Agriculture, (12), pp.102-105, 2011.

[3] LIN Quanlu , WANG Cuilin. A study of brand strategies on special agricultural products in the underdeveloped areas. Journal of Northwest Normal University (Normal University), (01), pp.119-121, 2007.

[4] LIN Quanlu. Study on industrialized management and brand strategy of characteristic agricultural products in underdeveloped areas. Research of Financial and Accounting, (04), pp.15-17, 2006.

[5] LU Linquan, WANG Cuilin, Exploring management strategy of characteristic agricultural products industrialization in underdeveloped area-taking Dingxi city for example. Science Economy Socirty, (01), pp.16-19, 2005.

[6] JIANG Guoping, Exploring the problem of industrialization of agriculture in the underdeveloped areas. Journal of Shanxi Agricultural University (Society Science Edition), (03), pp.210-212, 2004.

[7] YAN Jin, Study on industrialization of characteristic agricultural products in Dingxi city. Development, (07), pp.77-79, 2004. 